\title{
When Failing Doesn't Matter: A Narrative Inquiry into the Social Work Practice Learning Experiences of Black African Students in England
}

\author{
Prospera Tedam ${ }^{1}$ \\ ${ }^{1}$ Senior Lecturer in Social Work, University of Northampton, UK \\ Correspondence: Prospera Tedam, Senior Lecturer in Social Work, University of Northampton, UK. E-mail: \\ Prospera.Tedam@northampton.ac.uk \\ Received: January 27, 2014 \\ Accepted: February 12, 2014 \\ Online Published: February 15, 2014 \\ doi:10.5430/ijhe.v3n1p136 \\ URL: http://dx.doi.org/10.5430/ijhe.v3n1p136
}

\begin{abstract}
This paper reports the findings of a small-scale empirical study into the practice learning experiences of black African students of social work in England. Undertaken in the form of a pilot study, the findings reveal that practice learning experiences can be beneficial in enhancing skills and knowledge but can also cause distress, lower self-esteem and result in students feeling discriminated against. For participants, failing their practice learning appeared to be a far more pleasant outcome than undergoing the levels of disrespect and discrimination they believed they were subjected to on a regular basis during placements. Using elements of the critical race theoretical (CRT) framework, an attempt is made to conceptualise the narratives generated from participant interviews.
\end{abstract}

Keywords: Black African social work students, Practice learning, Student experience, Practice educators

\section{Introduction}

Universities and institutions of higher education in the UK and across the globe are prioritising the student experience as a key part of their recruitment and retention strategy. With growing numbers of university students studying in countries other than their own, various strategies are being introduced to support student learning and to encourage teaching practices that are culturally inclusive and relevant.

Social work education in England is delivered as a three- or four-year undergraduate programme or a two-year masters programme. A core requirement of the qualifying programme under the General Social Care Council (GSCC) was a minimum of 200 days in direct practice with service users in what is called practice learning, field education or practicum (Parker 2010). The current requirement is 30 days for the development of skills for practice and 170 in placement (College of Social Work 2012a).

In 2007 and again in 2009, the General Social Care Council (GSCC) found that after white British, students of black African ethnicity were the second largest ethnic group enrolled on social work qualifying programmes across England and Wales. Whilst this has been attributed to various schemes such as the Widening Participation agenda, the increase in black African students has been found across many academic disciplines. It has been noted by Singh (2011) that people of black African and Indian ethnicities participate more widely in higher education than other minority groups such as black Caribbeans and Bangladeshis, and this could in part explain the growth of black African students studying social work.

Quantitative studies by Hussein et al. (2008, 2009) found that overall in England students of black and ethnic minority backgrounds took longer to complete their social work degrees than white students. The reasons provided for this are varied and current research attention into these disparities is growing. A qualitative Scottish study (Hillen 2013) involving students, practice teachers and lecturers revealed similar patterns in terms of delayed progression of black African students and a disproportionately higher number of fails or terminations with particular reference to placement learning.

More recently, a London-based study of social work education concluded that BME students are more likley to fail, be withdrawn or be referred in their practice learning (Fairtlough et al. 2013).

This article will begin with a brief review of the literature and then move on to outline the study, and discuss and analyse the findings. 


\section{Literature review}

Research into the practice learning experiences of black African students studying social work in England is sparse. In fact, at the time two colleagues and I embarked on our initial research into the experiences of black African social work students at our university (Bartoli et al. 2008), existing research focused on the broader category of 'Black Minority Ethnic' (BME) and/or black students more generally. The aim of that study was to explore the experiences of black African students studying social work, and the findings revealed that this group of students faced particular challenges such as feeling 'homesick', financial commitments to relatives and family in the UK and abroad, ongoing caring responsibilities, health issues, and experiences of discrimination and racism (Bartoli et al. 2008).

This current study is driven by my ongoing inquiry into the experiences of this ethnic group within practice learning as the focus of my doctoral study.

Kadushin (1992) in the early 1990s, reported that social work students viewed their placement experiences as 'the most significant, most productive, most memorable component' of their qualifying training (1992: 11). My own study has revealed that placement experiences can also be remembered for the wrong reasons.

Whilst research suggests that on the whole practice educators (PEs) may be reluctant or find it emotionally challenging to fail students (Finch and Taylor 2013), it remains to be established whether this perceived reluctance relates to students of all ethnic groups.

A large study into diversity and progression on social work programmes in England, funded by the Department of Health and reported by Bernard et al. (2011), has confirmed that the practice learning environment presents a source of difficulty for BME students, often impacting on their progression.

Further studies by Bernard et al. (2013) in England focused on the experiences of marginalised groups studying social work. Lesbian and gay students, disabled students and BME students participated in this study. For the purposes of this paper, the findings in relation to the latter will be examined. BME students from across seven HEIs participated in this study. They described their experiences as blemished by racism and racist attitudes from their peers and from service users.

In a study of the impact of gender on failing students, cultural differences, patriarchy and authority were reported as being causes of poor relationships between PEs and students. The study concluded that male students and students from BME backgrounds are more likely to fail practice placements than any other group (Furness 2012).

Fletcher et al. (2013) argue that HEIs in England appear to prioritise equality in relation to access to higher education but compromise the strategies needed to afford equality of outcomes for their students. Such a situation is contributing to the differential outcomes for marginalised students studying social work in England. It could be suggested that empirical studies such as this current study aim to highlight these inconsistencies and also to offer potential solutions to addressing them.

These experiences faced by BME students of social work are not peculiar to the UK, nor indeed are these experiences limited to social work education. Zuchowski et al. (2013), writing about the experiences of Aboriginal social work students in field education in Australia, suggest that oppressive practices in the field often resulted in students feeling hurt and distressed. From a broader UK perspective, lower attainment outcomes have been reported for BME students across a range of academic disciplines (Berry and Loke 2011; Stevenson 2012).

\section{Practice learning in the UK}

The social work profession is continuously undergoing scrutiny, change and review. These changes affect not only social work practice but also social work education (College of Social Work 2012a), resulting in the training being increased from a one-year certificate qualification in social work (CQSW) to a two-year diploma in social work (DipSW) to a three- to four-year degree in social work. During all these changes, the centrality of practice learning has continued to be highlighted as a key determinant in the 'professional formation' of students (Walker et al. 2008: 28). Consequently, the current degree provision includes a 50 per cent component of practice learning (Wilson et al. 2008), although there has been a suggestion that this should be increased to ensure that qualifying students are adequately equipped for the task of supporting and advocating on behalf of service users. There are a number of people involved in supporting, assessing and enabling the learning of the student, the primary person being the PE. The PE is usually, but not always, a qualified social worker who has undergone specific training to enable and support the learning of students. The PE works alongside the social work student, identifying and providing opportunities for learning, personal growth and self-reflection (Parker 2010). The PE is also responsible for the formative and summative assessment of the social work student with specific reference to the quality of their practice 
with service users. Throughout the practice-learning period, the student is expected to engage and work with their PE to identify any areas of particular strength, difficulty and competence. It is therefore unsurprising that the quality of the relationship between a social work student and their PE is of immense importance, as is the influence of ethnic diversity on the relationship (Tedam 2012a).

\section{Research design}

A qualitative narrative approach was used for this study as it allowed for a rich description of placement experiences and an exploration of the meaning participants attached to these experiences. Narrative approaches can be used as a method of data collection and also as a philosophical approach (Riessman 2008). It amplifies voices that would otherwise have been silenced (Trahar 2013) and utilises story-telling as a way of communicating reality (Riessman 2008).

Czarniawska, (2004: 17) argues that "narrative is understood as a spoken or written text giving an account of an event/action or series of events/actions, chronologically connected', a definition that reflects the rationale for its use in this pilot study.

Participants were purposively recruited in that they had to meet certain criteria for inclusion in the study. They had to be 1) of black African ethnicity, 2) enrolled on a recognised qualifying social work programme anywhere in England, and 3) should have had at least one practice learning opportunity. Using personal contacts as a starting point, word of mouth generated interest in this research and letters of invitation to participate in the study were sent out. Five potential participants came forward and the selection of these two participants was reached due to their availability for interviews by the schedule I was working to. Acknowledgement emails were sent to the other three participants, thanking them for their interest and requesting their permission to retain their details until a later stage when their participation would be needed for the doctoral study.

Individual semi-structured interviews were undertaken lasting an average of 40 minutes each. These were audio-taped and interview notes were taken. A thematic analysis of the transcripts was undertaken to find common themes across both participants' narratives, utilising what Riessman (2008) refers to as a concentration on 'what' was said and not 'how' the narratives were told.

Once the themes were identified, relevant tenets of CRT were used as the interpretive framework within which the placement experiences of black African students of social work were situated.

Ethical approval was granted by the School of Health Ethics Committee, University of Northampton in December 2013.

The interview protocol can be found in the Appendix.

\section{Description of sample}

Baez (2002) cautions against changes to facts such as age, sexuality, gender and race as they can have a profound impact on the findings of the study. Names, on the other hand, can be changed to protect anonymity, and pseudonyms are an effective protective strategy for maintaining participant anonymity. For this reason, the participants in this study are referred to as Ramatu and Shola.

Two female participants took part in this pilot study. They describe themselves as black African and are originally from two different countries in West Africa. They each study at a different HEI in the Midlands and no student from the author's university was involved. Both participants were settled in the UK for over 10 years before enrolling onto their undergraduate social work programmes. One participant had a degree-level qualification in a related social science subject.

\section{Findings}

The two participant narratives provide significant insight into their experiences of practice learning and will now be examined using a thematic approach across both narratives.

The six emergent themes from the interviews are:

- a lack of confidence in their skills, knowledge and abilities

- finding it easy to fail black African students

- lack of support

- disrespect and patronising behaviour 
- $\quad$ racism and unfair treatment

- over-scrutiny.

\subsection{A lack of confidence in their abilities and capabilities}

Both participants expressed concern that their practice learning experiences were tainted by what they perceived as a lack of confidence in their skills and knowledge by PEs and colleagues in their placement settings.

They stated that written work, which was of good quality, was often viewed as not their own work. For Ramatu, who did not have access to an official email address, there appeared to be no hurry to provide her with access. When she queried this, the response suggested that her PE did not feel she could provide it as it would be unsupervised. Instead, the PE required Ramatu to pass all written correspondence, no matter how insignificant, to her for 'approval'. For a PE who often worked away from the office, this strategy had the potential not only to slow the pace of work but also to reinforce their lack of confidence in Ramatu's ability to work without being micro-managed.

Similarly, Shola shared that her PE had set out to undermine and disregard her by ignoring the previous placement report, which provided evidence of her growth and development as a social worker and contained constructively stated areas for development. Each attempt to draw her PE's attention to the contents of her previous placement report proved futile and when directly questioned about this, the PE replied that she had high standards and did not wish these to be compromised by reading a previous placement report.

\subsection{Finding it easy to fail black African students}

Participants felt that PEs appeared to 'find it easy' to fail black students. Shola commented that she had noticed her PE would number her reflective logs even after corrections and amendments were made. When she questioned this practice her PE informed her that the purpose was to 'see how many times it would take me to get it right', and also that such information would serve 'as evidence if she were to recommend a failed placement'. Shola became acutely aware of what was going on in this placement as 'Within a few weeks it was clear that nothing I was going to do would be OK.' The thought that a PE could be talking about failure in the first few weeks of placement led Shola to conclude that some PEs 'find it easy to fail black students and difficult to pass us'.

\subsection{Lack of support}

Both participants expressed the view that a lack of support from colleagues and the PE impacted negatively on their experiences of practice learning. For Ramatu, her first 70-day placement in a different setting was described as positive and enjoyable, largely as a result of the levels of support she received from various colleagues and her PE and what she describes as a 'friendly and inclusive environment'. Her second placement, however, appeared to be less supportive, with an onsite/offsite arrangement which did not meet her needs. The nature of the agency also meant that the onsite supervisor was out of the office frequently and other colleagues appeared to be busy and inaccessible.

For Shola, the PE is reported to have been 'very nice in public' but overly critical and unsupportive in private. The PE also took exception to the view held by the university that Shola was a student working to high standards, with above average intellect and potential.

A small-scale study by Lefevre (2005) revealed that students viewed the lack of support from their PEs as resulting in the poor relationship between them and their PE, which impacted on their overall experiences of their practice learning.

\subsection{Disrespect and patronising behaviour}

Narratives from both participants indicate their views that specific PEs demonstrated disrespect and patronising behaviour towards them during the period of their practice learning opportunity. Ramatu offers an example of this: 'My site manager often worked away from the office and so I would have to ring her about different things. She often put the phone down on me, saying she didn't understand my accent.'

The tone, pitch and pronunciation of words by people for whom English is an additional language is, according to Harrison (2012) regularly subjected to evaluation by native speakers of English. This PE's regular practice of putting the phone down on this student undertaking a practice learning opportunity fails to acknowledge and respect diversity as well as ethnic and linguistic differences which exist in contemporary Britain. This leaves some concern as to the way in which this particular manager would respond to a service user whose accent was different to theirs via the telephone. Bourdieu (1991) asserts that the ways in which people speak and the ability to use language in ways that are socially acceptable and desirable play an important role in access to employment. As a potential future 
employer of social workers this manager's attitude to this student could be construed as disrespectful and overtly racist.

For Shola, a constant reminder by the PE that English was her additional language resulted in sometimes irrelevant deflection from matters directly related to the placement and her learning, resulting in valuable time and energy being wasted. For example, the bulk of one supervision session focused on the discussion about Shola's use of the word 'refuse' in an assessment of a vulnerable family. In the end Shola felt compelled to look up the meaning of the word and although she had used it correctly, the PE suggested that she use the word 'declined' instead. In Shola's own words, 'I found myself looking up the meaning of the word "refuse" and realised I had used it correctly but because I wanted to end the disagreement, I changed it.' Throughout this disagreement, the PE did not provide a satisfactory rationale for her stance but instead used what I call 'the expert first language user privilege' to undermine Shola.

Shola also alluded to another example where she had received commendation from a teacher for a report she had completed and shared at a planning meeting. To her surprise, her PE challenged the teacher's view that Shola would make a 'good social worker', thereby dismissing the teacher's professional judgement. Shola felt that her PE would never validate her skills and abilities, no matter how hard she tried. These sorts of responses mirror what Sue (2005) refers to as 'micro aggressions' where verbal, non-verbal and subtle put-downs are used as a means to perpetuate disregard for, and to undermine, minority groups.

\subsection{Unfair treatment}

Again, both participants alluded to what they perceived as unfair treatment directed at them from their PEs. As mentioned earlier, Ramatu stated that she was not given a work email address, nor was there one for general use. She therefore had to rely on her colleague's email account (a permanent member of staff) to send formal letters and other correspondence to service users. This, she argued, disadvantaged her in terms of workload and engagement with service users, something that was later used as evidence to recommend a fail. Despite the agency being aware of this, her colleagues did not support her when she raised it as an issue. Of particular significance was what Ramatu described as the lack of opportunity for learning to take place due to the actions of her PE. She explained that she had written up her evidence in relation to the Professional Capabilities Framework (PCF) (College of Social Work 2012a) and presented this to her PE who then accused her of 'lying' about what she had written. The PE was of the view that the tasks were completed in collaboration with other members of the team and that Ramatu had represented the evidence as though she had completed the tasks on her own. The PE is reported to have proceeded to suggest that HCPC codes of conduct had been contravened and labelled Ramatu as 'dishonest'.

\subsection{Over-scrutiny}

The issue of perceived over-scrutiny of black African social work students has been cited in another related study (Fairtlough et al. 2013) and is not new. For these participants, feeling over-scrutinised took many forms. Ramatu stated that it was her colleague who would give their manager a report of work Ramatu had undertaken each day. This often included work or tasks she had been unable to complete. The emphasis appeared to be about uncompleted tasks, with little recognition or regard for the quality and standards of work that had been completed. She remains unsure about why the manager encouraged such behaviour, which in effect undermined Ramatu and gave the impression that she was incapable of self-reporting. This also had the potential to reinforce a workplace culture in which permanent employees could scrutinise the daily work of social work students without a clear or transparent remit to their involvement.

Ramatu said she kept a log of her daily activities and the times during which she had undertaken those tasks. Her PE would painstakingly go through the daily activity sheet asking questions such as, 'Did it really take you one hour to complete the forms with the service user?' On one occasion, Ramatu responded by saying 'yes it did' and her PE is alleged to have said 'that was a rhetorical question, I didn't expect an answer'. This reaction from the PE could be interpreted variably. From the authors perspective, the response could be taken to mean Ramatu did not know the difference between a rhetorical question and one requiring a response or that the PE disbelieved the length of time taken to complete this task. In the absence of a rationale by the PE, it is possible to conclude that the quality of the relationship between Ramatu and her PE was poor.

The study by Fairtlough et al. (2013) revealed that BME students felt more scrutinised than white students whilst on placement and less supported when any issues or difficulties arose during placement, which mirrors Ramatu's own experience. 


\section{Discussion}

Respondents in this study gave accounts of over-scrutiny, discrimination, low expectations and a general lack of support in relation to their practice learning opportunities. It is not within the scope of this paper to attempt to rationalise the acts or omissions by PEs and other people involved in these students' placement learning; neither is it consistent with narrative inquiry to ask informants why they felt they experienced what they did. Instead, the aim is to provide these black African students of social work an opportunity to counter existing stories about their achievements or failures on placement, which may have been told by others. The experiences, discussed around major themes, are unsurprising and perhaps go some way in explaining why this group of students generally take longer to complete their studies. Ramatu, for example, will require another placement whilst Shola's instigation of a termination of her placement went through a series of inquiries and investigations by the university, which eventually did not uphold the fail grade proposed by the PE. The length of time taken by all stakeholders to resolve both cases impacts on completion and graduation timescales for students. In addition to this, final degree classifications are likely to be impacted by repeat placements and all this ultimately will have repercussions on employment and employability, another area of growing disadvantage for graduates from BME backgrounds (Richardson 2008). The emotional impact of these practice learning experiences on participants requires further detailed analysis; however, for participants in this study, the extent of emotional impact was apparent through their feelings of hopelessness and helplessness, resulting in Ramatu and Shola becoming tearful during interviews.

The new Practice Educator Practice Standards (PEPS), introduced by the College of Social Work and fully implemented by October 2013, requires PEs, among other things, to 'recognise and work to prevent unjustifiable discrimination and disadvantage in all aspects of the assessment process, and counter any unjustifiable discrimination in ways that are appropriate to their situation and role' and also to 'respect and value the uniqueness and diversity of learners and recognise and build on their strengths, and take into account individual learning styles and preferred assessment methods' (College of Social Work 2012a: 11).

It is unclear how this particular standard will be evidenced by the PEs referred to in this study. The findings indicate that neither Ramatu nor Shola felt valued or respected by their PE and their articulated experiences of discrimination and disadvantage bear this out. Ramatu and Shola share some strategies below, which they believe will result in more positive placement experiences by black African students of social work.

\section{A critical race perspective}

Critical race theory (CRT) emerged from the United States of America in legal discourse in the 1970s. It sought to provide a framework for understanding the impact of race and racism on outcomes for black people. Proponents argued that despite legislation and policy prohibiting racism, it continued to flourish in the USA (Delgado 1995). Its application has less of a history in the UK, with researchers in sports and education disciplines leading in the application of CRT in these areas (see Gillborn 2008; Hylton 2005; Rollock 2012).

Solorzano and Yosso (2001: 71) have used CRT to "challenge the dominant discourse on race and racism as it relates to education by examining how educational theory and practice are used to subordinate certain racial and ethnic groups'. CRT provides opportunities for researchers to consider the role of race and racism, which engulfs the educational experiences and outcomes for black people (Parker and Lynn 2002). Consequently, in social work, CRT seeks to provide, explain and describe experiences and perspectives of black people in all facets of social work practice and education.

In HEIs in England, league tables, progression and attainment data provide a rationale for the development of strategies and processes to improve outcomes for BME students. This, in the author's view, represents the interest convergence tenet of CRT, where better educational experiences and outcomes for BME students impact on the wider institutional outcomes and, ultimately, league tables and attainment data (Broecke 2012).

Another tenet of CRT, counter-story-telling allows black people to tell their stories, choosing and using language which they feel comfortable with and providing alternative explanations of their experiences. It has been argued that these counter stories are often told; however, they have been misinterpreted, discounted or minimised in academic discourse (Milner 2007). This current study provides an opportunity for these rich narratives to be prioritised and privileged with the hope that social work education will seek to actively address and challenge behaviours and attitudes which impact on the progression and attainment of black African social work students in England.

The intersectionality of race and gender, according to proponents of CRT, is an important tenet to consider and is relevant to this current study. Both participants, their PEs and onsite supervisors are female. Ramatu described her PE's ethnicity as 'Asian', while Shola stated that her PE was of 'white British' ethnicity. Being black and female 
have intersected to produce the unique experiences for both participants, much of which has already been discussed in this paper.

\section{Implications for social work education}

This study has highlighted key areas of concern for black African students studying social work in England. The two participants proposed some solutions towards enhancing the practice learning experiences. Whilst these are varied and sometimes polarised, they offer alternative ways to thinking, working and assessing black African students of social work undertaking social work placements.

The issue of support, not just from the PE but also colleagues and other members of the team, was highlighted as crucial to improving their practice learning experiences.

Another area was around support from the university. In the case of Ramatu, the university upheld the failed placement recommended by the PE and proceeded to instigate the end of placement processes.

In Shola's case the PE's assessment and recommendation for a fail grade were not upheld by the university, which felt that the evidence provided by the PE did not justify a fail, especially as a number of other professionals provided positive feedback and evaluation of Shola and her achievements as a social work student. Further inquiries into the particular PE revealed a string of failed students, all of BME backgrounds.

Parker (2005) recommends that research findings should be used constructively and not merely for the academic enhancement of the researcher, and it is hoped that these findings are widely disseminated to provide PEs, HEIs and others involved in social work education with further insight into the experiences faced by some members of an ethnic minority group.

One strategy which Goldingay (2012) proposes as useful is that HEIs spend time in pre-placement planning and support for international students as her research evidenced the value of such a strategy.

Research into strategies to enhance placement experiences and outcomes for black African students is ongoing as part of the larger doctoral study.

\section{Limitations of the study}

This study has considered the practice learning experiences of two black African undergraduate social work students in England; consequently, it has its limitations. First, the sample size is small $(\mathrm{n}=2)$, the views of the PEs and others involved in the practice learning experience of these students were not sought and so these findings are not independently verified but rather relied on self- reporting by participants, which for any qualitative study poses issues of reliability. In addition, these findings are not intended as generalisable to the wider black African social work student population in England.

The author's own biography of being black African and female could be perceived as privileging a certain type of reality and reporting findings to fit with this reality. However, as a researcher, ethically bound by the values and codes, I have made the necessary safeguards such as requiring the participants to see and confirm the transcripts prior to using the data.

\section{Conclusion}

The purpose of this study was to understand from participants' perspectives their experiences of practice learning in their social work qualifying programme. The fact that at some point the issue of failing a placement consumed their interviews is incidental. Although they expressed it differently, both participants suggested that failing a placement was preferred over and above the daily feeling of hopelessness, helplessness, despair and disrespect.

For Ramatu who 'felt relieved when they told me my placement was terminated', the termination of her placement could not have come at a better time. In Shola's case she 'packed and left' as she did not want to give the PE the 'joy of seeing me [her] cry'.

For both participants, social work professional values of being non-judgmental, respecting the uniqueness of individuals and non-oppression within their practice learning environments are undermined by the existence of racism and racist behaviour evidenced by acts or omissions by their PEs and others involved in their practice learning.

Research by Fletcher et al. (2013) found that the emphasis on equality and fairness was heavily weighted towards access into HEIs rather than a focus on outcomes for black and other minority groups studying social work. 
Ramatu and Shola have provided narratives that highlight examples of direct and indirect racism; discrimination and unfair treatment which they said resulted in poor placement experiences. These stories according to Delgado (1989) will be of benefit to the majority race who can 'enrich their own reality' (p.2439) through hearing stories from members of this minority group.

\section{References}

Baez, B. (2002). 'Confidentiality in qualitative research: Reflections on secrets, power and agency.' Qualitative Research, 2, 35-58. http://dx.doi.org/10.1177/1468794102002001638

Bartoli, A., Kennedy, S. \& Tedam, P. (2008). 'Practice learning: Who is failing to adjust? Black African student experience of practice learning in a social work setting.' Journal of Practice Teaching and Learning, 8, 2, 75-90. http://dx.doi.org/10.1921/81134

Berry, J. \& Loke, G. (2011). Improving the Degree Attainment of Black and Minority Ethnic Students. York: ECU/HEA. Books.

Bernard, C., Fairtlough, A., Fletcher, J. \& Ahmet, A. (2011). 'Diversity and progression among social work students in England.' Online at www.kcl.ac.uk/sspp/kpi/scwru/dhinitiative/projects/bernardetal2011diversityfinalreport.pdf [accessed on 27 December 2013].

Bernard, C., Fairtlough, A., Fletcher, J. \& Ahmet, A. (2013). 'A qualitative study of marginalised social work students' views of social work education and learning.' British Journal of Social Work. http://dx.doi.org/10.1093/bjsw/bct055

Bourdieu, P. (1991). Language and Symbolic Power. Cambridge: Polity Press.

Broecke, S. (2012). 'University rankings: Do they matter in the UK?' Education Economics. http://dx.doi.org/10.1080/09645292.2012.729328

College of Social Work (TCSW). (2012a). Practice Educator Professional Standards for Social Work. London: TCSW. Online at www.tcsw.org.uk [accessed on 11 February 2014].

College of Social Work (TCSW). (2012b). 'Professional Capabilities Framework'. Online at www.tcsw.org.uk/pcf.aspx [accessed on 11 February 2014]

Czarniawska, B. (2004). Narratives in Social Science Research. London: Sage.

Delgado, R. (1989). 'Storytelling for oppositionists and others: A plea for narrative.' Michigan Law Review, 87, 2411-2441. http://dx.doi.org/10.2307/1289308

Delgado, R. (Ed.). (1995). Critical race theory: The cutting edge. Philadelphia: Temple University Press.

Fairtlough, A., Bernard, C., Fletcher, J. \& Ahmet, A. (2013). 'Black social work students' experiences of practice learning: Understanding differential progression rates.' Journal of Social Work. http://dx.doi.org/10.1177/1468017313500416

Finch, J. \& Taylor, I. (2013). 'Failure to fail? Practice educators' emotional experiences of assessing failing social work students.' Social Work Education, 32, 2, 244-258. http://dx.doi.org/10.1080/02615479.2012.720250

Fletcher, J., Bernard, C., Fairtlough, A. \& Ahmet, A. (2013). 'Beyond equal access to equal outcomes: The role of the institutional culture in promoting full participation, positive intergroup interaction and timely progression for minority social work students.' British Journal of Social Work. http://dx.doi.org/10.1093/bjsw/bct081

Furness, S. (2012). 'Gender at work: Characteristics of “failing” social work students.' British Journal of Social Work, 42, 480-499. http://dx.doi.org/10.1093/bjsw/bcr079

General Social Care Council (GSCC). (2007). Social Work Education in England: Delivering Quality, Recognising Success. Social Work Education Quality Assurance Report. London: GSCC.

General Social Care Council (GSCC). (2009). Raising Standards in Social Work Education in England 2007-8. London: GSCC.

Gillborn, D. (2008). Racism and Education: Coincidence or Conspiracy. Abingdon: Routledge.

Goldingay, S. (2012). 'Getting it right in the mix: Teaching social work practice skills inclusively to diverse student groups.' Journal of Social Inclusion, 3, 1, 101-116. 
Harrison, G (2012). “"Oh you've got such a strong accent”: Language identity intersecting with professional identity in the human services in Australia.' International Migration, 51, 5, 192-204. http://dx.doi.org/10.1111/imig.12005

Hillen, P. (2013). Enhancing Outcomes for Black and Minority Ethnic Social Work Students in Scotland. University of Edinburgh.

Hussein, S., Moriarty, J. \& Manthorpe, J. (2009). Variations in Progression of Social Work Students in England: Using Student Data to Help Promote Achievement: Undergraduate Full-time Students' Progression on the Social Work Degree. Online at www.kcl.ac.uk/sspp/kpi/scwru/pubs/2009/husseinetal2009Variations.pdf [accessed on 27 December 2013].

Hussein, S., Moriarty, J., Manthorpe, J. \& Huxley, P. (2008). 'Diversity and progression among students starting social work qualifying programmes in England between 1995 and 1998: A quantitative study. British Journal of Social Work, 38, 1588-1609. http://dx.doi.org/10.1093/bjsw/bcl378

Hylton, K. (2005). '“Race”, sport and leisure: Lessons from critical race theory.' Leisure Studies, 24, 1, 81-98. http://dx.doi.org/10.1080/02614360412331313494

Kadushin, A. (1992). Supervision in Social Work. New York: Columbia University Press

Lefevre, M. (2005). 'Facilitating practice learning assessment: The influence of relationship.' Social Work Education, 24, 5, 565-583. http://dx.doi.org/10.1080/02615470500132806

Milner, H.R. (2007). 'Race, culture and researcher positionality: Working through dangers seen, unseen and unforeseen.' Educational Researcher, 36, 7, 388-400. http://dx.doi.org/10.3102/0013189X07309471

Parker, I. (2005). Qualitative Psychology: Introducing Radical Research. Maidenhead: Open University Press.

Parker, J. (2010). Effective Practice Learning in Social Work. 2nd edn. Exeter: Learning Matters.

Parker, L. and Lynn, M. (2002). 'What's race got to do with it? Critical race theory's conflict with connections to qualitative research methodology and epistemology.' Qualitative Inquiry, 8, 7-22.

Richardson, J.T.E. (2008). 'The attainment of ethnic minority students in UK Higher Education.' Studies in Higher Education, 33, 1, 33-48. http://dx.doi.org/10.1080/03075070701794783

Riessman, K.C. (2008). Narrative Methods for the Human Sciences. London: Sage.

Rollock, N. (2012). 'The invisibility of race: Intersectional reflections on the liminal space of alterity.' Race Ethnicity \& Education, 15, 1, 65-84. http://dx.doi.org/10.1080/13613324.2012.638864

Singh, G. (2011). Black and Minority Ethnic (BME) Students' Participation in Higher Education: Improving Retention and Success. York: The Higher Education Academy. Online at www.heacademy.ac.uk/resources/detail/inclusion/Ethnicity/BME_synthesis [accessed on 27 December 2013].

Solorzano, D.G. \& Yosso, T.J. (2001). 'From racial stereotyping and deficit discourse toward a critical race theory in teacher education.' Multicultural Education, 64, 218-231.

Stevenson, J. (2012). Black and Minority Ethnic Student Degree Retention and Attainment. York: The Higher Education Academy. Online at www.heacademy.ac.uk/resources/detail/retention/bme_summit_report [accessed on 11 February 2014].

Sue, D.W. (2005). 'Racism and the conspiracy of silence.' Counselling Psychologist, 33, 100-114. http://dx.doi.org/10.1177/0011000004270686

Tedam, P. (2012). The MANDELA model of practice learning: An old present in new wrapping? Journal of Practice teaching and learning. 11 (2) 19-35

Trahar, S. (2013). Contextualising Narrative Inquiry. Developing Methodological Approaches for Local Contexts. Abingdon: Routledge.

Walker, J., Crawford, K. \& Parker, J. (2008). Practice Education in Social Work: A Handbook for Practice Teachers, Assessors and Educators. Exeter: Learning Matters.

Wilson, G., Walsh, T. \& Kirby, M. (2008). 'Developing practice learning: Student perspectives.' Social Work Education, 27, 1, 35-50. http://dx.doi.org/10.1080/02615470601141359

Zuchowski, I., Savage, D., Miles, D. \& Gair, S. (2013). 'Decolonising field education: Challenging Australian social work praxis.' Advances in Social Work and Welfare Education, 15, 1, 47-62. 


\section{Appendix: Interview protocol}

1. Please describe your practice learning setting(s):

a) What is/was the duration of this placement?

b) Type of placement (statutory, voluntary, private, etc.)

c) Service user group (children, adults, mental health, housing, asylum, etc.).

2. Tell me about experiences of practice learning on your social work qualifying programme.

3. What do you feel are the factors that contribute to a positive social work placement experience?

4. What do you feel are the factors that might prevent a positive social work placement experience?

5. Tell me about some of the ways you feel your skills have developed through practice learning.

6. What strategies would you share with new black African students about to start their social work training? 